\title{
Basal cell naevus syndrome and intracranial meningioma
}

\author{
PS MORTIMER, DP GEANEY, ${ }^{*}$ K LIDDELL, $†$ RPR DAWBER \\ From the Department of Dermatology, The Slade Hospital, Oxford, MRC Unit and Clinical Trials Unit, * \\ University Department of Clinical Pharmacology, Radcliffe Infirmary, Oxford, and the Department of \\ Dermatology, $\dagger$ Eastbourne District General Hospital, Eastbourne, UK.
}

SUMMARY Two cases of the basal cell naevus syndrome in association with an intracranial meningioma are described and the relationship discussed.

The basal cell naevus syndrome is a condition with autosomal dominant inheritance of high penetrance and variable expressivity. ${ }^{1}$ It is characterised by multiple basal cell naevi, jaw cysts, cutaneous pits of the hands and feet, vertebral and rib abnormalities, and intracranial calcification. ${ }^{2}$ The basal cell naevi usually appear in childhood, particularly over the face, neck, trunk and upper limbs. There may be few to hundreds varying in size and appearance from small papules to larger nodules, sometimes with pigmentation. Clinically the tumours resemble pigmented moles (naevi). There may be a gross resemblance to neurofibromatosis. However, microscopically, the tumours cannot be differentiated from ordinary basal cell carcinomas. In addition, central nervous system abnormalities have been described since the first case report, in which agenesis of the corpus callosum was found. ${ }^{3}$ We now describe two cases of basal cell naevus syndrome associated with an intracranial meningioma.

Case 1

A girl aged 14 years developed cysts in her jaw requiring numerous operations for their removal. Two years later she had a basal cell carcinoma removed from her nose. Subsequently, she had five more identical lesions excised from different sites on her face. When aged 47 , she developed simple partial seizures affecting the left upper limb with secondary generalisation. Examination revealed ocular hypertelorism, frontal bossing, palmar pits and multiple basal cell naevi on the face (fig 1). In addition, she had

Address for reprint requests: Dr PS Mortimer, Department of Dermatology, The Slade Hospital, Headington, Oxford OX3 7JH, UK.

Received 1 August 1983

Accepted 14 September 1983 a mild left hemiparesis. Skull radiographs demonstrated heavy calcification of the falx cerebri, flecks of calcium in the parasagittal region and an osteolytic lesion in the right fronto-parietal region. Right carotid angiography confirmed the presence of a right fronto-parietal spaceoccupying lesion with no pathological circulation. At craniotomy, a tumour $6 \mathrm{~cm}$ in diameter was excised which histology proved to be a meningioma. Her son also has basal cell naevus syndrome and has had multiple basal cell carcinoma lesions excised.

\section{Case 2}

This patient first developed a basal cell carcinoma on the left temple at the age of $\mathbf{4 0}$ years. The tumour was excised and the site treated with superficial radiotherapy. Two years later, he presented with four similar lesions close together which were treated by a radium implant. At the age of 44 he was given a further course of superficial radiotherapy to a basal cell carcinoma of the left inner canthus. Later that year he gradually developed difficulty in concentration, slurred speech and weakness and numbness of the right hand. Examination revealed postirradiation changes in the skin of the temple with adjacent hair loss, mild aphasia and dysarthria, and weakness and numbness of the right hand. Skull radiographs showed calcification of the falx cerebri. Left carotid angiogram demonstrated a left parietal space occupying lesion with some vascular supply from the external carotid artery. At craniotomy, a tumour $6.5 \mathrm{~cm}$ in diameter was removed. Histology showed the tumour to be a meningioma of transitional type with marked cellularity and numerous mitotic figures suggestive of malignancy. At the age of 45 years he had developed several further basal cell carcinoma lesions. It was noted that he had palmar pits, frontal bossing and the diagnosis of basal cell naevus syndrome was made. Radiographs of the chest and cervico-thoracic spine demonstrated multiple rib anomalies and extensive spina bifida from the second to the fourth thoracic vertebrae. To 


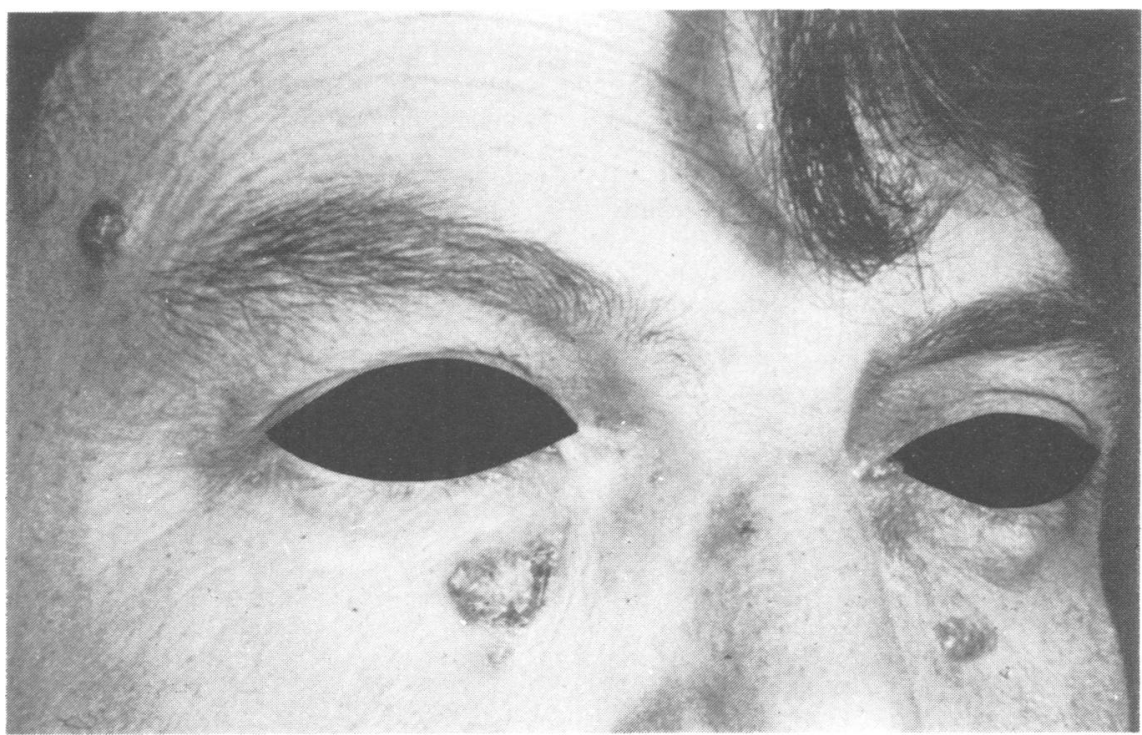

Fig 1 Case 1 showing three naevoid basal cell carcinomas.

date, at least 25 basal cell carcinomas have been treated. His mother has also been treated for two such lesions.

\section{Discussion}

Basal cell naevus syndrome has been compared to other neurocutaneous syndromes such as neurofibromatosis and tuberous sclerosis. ${ }^{34}$ There have been no further reports of associated agenesis of the corpus callosum since the initial case report, but various other neurological abnormalities have been described. Intracranial calcification occurring most frequently in the falx cerebri and less commonly in the tentorium cerebelli and petroclinoid ligaments, is found in more than $80 \%$ of cases. ${ }^{2}$ Cases of associated intracerebral cysts ${ }^{5}$ and choroid plexus cysts $^{6}$ and communicating hydrocephalus ${ }^{7}$ have been reported. Intracranial neoplasms have also been described, particularly medulloblastoma, and development of this tumour may actually precede the appearance of the skin lesions. ${ }^{8} \mathrm{~A}$ single case associated with a cerebellar astrocytoma ${ }^{9}$ and two cases with a meningioma have been described. ${ }^{10} 11$ Both meningiomas were incidental post-mortem findings, and in one case there was also a craniopharyngioma.

The finding of four meningiomas, including the two reported here, suggests that development of the tumours is part of the syndrome. Unlike medulloblastomas, meningiomas in the basal cell naevus syndrome appear to present relatively late, the four patients described all being over 40 years old. It is interesting that our second case had extensive radiotherapy to the region of the left temple prior to the discovery of the left parietal meningioma. Patients with basal cell naevus syndrome appear to be particularly predisposed to tumour formation following radiotherapy. Children with basal cell naevus syndrome and medulloblastoma who, following surgery, were treated with radiotherapy to the neuraxis, all developed multiple basal cell carcinomas in the irradiated areas within six months to three years of radiotherapy.12 Fibrosarcoma of the ovary has also been described in one of these children following neuraxis irradiation, and fibrosarcoma of the jaw following local radiotherapy to mandibular cysts in two adult patients. ${ }^{311}$ Meningioma development in the basal cell naevus syndrome is probably a reflection of a genetic propensity for tumour formation which may be augmented by local radiotherapy.

We thank Mr B Crymble, Hurstwood Park Hospital, East Grinstead, and Mr M Briggs and Dr J Oxbury, Radcliffe Infirmary, Oxford, for help in the management of these patients.

\section{References}

${ }^{1}$ Gorlin RJ, Sedano HO. The multiple naevoid basal cell carcinoma syndrome revisited. Birth Defects 1971;7:140-8.

${ }^{2}$ Howell JB, Anderson DE. Commentary: The naevoid 
basal cell carcinoma syndrome. Arch Dermatol 1982;118:824-6.

${ }^{3}$ Binkley GW, Johnson HH Jr. Epithelioma adenoides cysticum, basal cell nevi, agenesis of the corpus callosum and dental cysts: A Clinical and Autopsy Study. Arch Dermatol Syphiliol 1951;63:73-82.

${ }^{4}$ Hermans EH, Grosfeld JCM, Spaas JAJ. The fifth phacomatosis. Dermatologica 1965;130:446-76.

5 Taylor WB, Anderson DE, Howell JB, Thurston CS. The naevoid basal cell carcinoma syndrome. Autopsy findings. Arch Dermatol 1968;98:612-4.

' Kahn LB, Gordon W. The basal cell naevus syndrome: report of a case. $S$ Afr Med J 1967;41:832-5.

${ }^{7}$ Gorlin RJ, Yunis JT, Tuna M. Multiple naevoid basal cell carcinoma, odontogenic keratocysts and skeletal anomalies. Acta Dermat Veneriol (Stockh) 1963;43:39-55.

${ }^{8}$ Neblett CR, Waltz TA, Anderson DE. Neurological involvement in the naevoid basal cell carcinoma syndrome. J Neurol 1971;35:577-84.

${ }^{9}$ Cawson RA, Kerr GA. The syndrome of jaw cysts, basal cell tumours and skeletal anomalies. Proc $R$ Soc Med 1964;57:799-801.

${ }^{10}$ Stoelinga PJW, Peters JH, Van De Staak WJB, Cohen MM. Some new findings in the basal cell nevus syndrome. Oral Surgeon 1973;36:686-92.

"Tamoney HJ Jr. Basal cell nevoid syndrome. Am Surg 1969;35:279-83.

12 Strong LC. Genetic and environmental interactions. Cancer 1977;40:1861-6. 